\title{
К вопросу о картине «Сражение под Смоленском» (1846) Петера Хесса из собрания Государственного Эрмитажа
}

\begin{abstract}
Аннотаиия. Предметом исследования является, с одной стороны, история появления реставрачионной записи, существуюшей в настоящий момент на картине Петера Хесса “Сражение под Смоленском", а с другой сторонъ, деятельность Николая I по мемориализачии военной истории России. Особое внимание уделяется истории создания в Зимнем дворие парадной анфилады «комнат военной живописи», важной частью которой была рассматриваемая картина. Объектом исследования является офиииальный вариант истории Отечественной войны 1812 года, создававшийся в 1840-1850-е годы под прямым контролем императора. Методологической основой исследования является системное рассмотрение исторических, в том числе изобразительньх, источников и фактов, полученных из ранее неизвестных архивных документов. Основными результатами проведенного исследования является отнесение существующей на картине записи к первой половине ХХ века и переоиенка роли этого прочзведения Хесса для николаевской эпохи. Актуальность полученнъцх результатов обусловлена как их прикладным значением (для музейной реставрачии), так и теоретическим, позволяюшим переосмыслить кониепиию «народной войны» в истории России первой половинъ ХІХ века. Господствовавший в историографии Отечественной войнъ эпохи Александра I взгляд на роль простого народа в войне претерпел существеннъе изменения при дворе Николая I и нашел отражение на картине «Сражение под Смоленском».
\end{abstract}

Ключевые слова: Петер Хесс, Николай I, Отечественная война, Зимний двореи, реставрачия, Смоленск, Эрмитаж, батальная живописъ, А. И. Михайловский-Данилевский, Л. И. Киль.

Abstract. The research subject of the article is, on the one hand, the history of the restoration corrections to the canvas of "The Battle of Smolensk" by Peter Hess. On the other hand, the article examines the practice of commemorating Russia's military history during the period of Nicholas I. Particular attention is paid to the history of creating the "Rooms of Battle Paintings" in the Winter Palace, which centered around the named picture. The article's object of research is the official version of the history of the Patriotic War of 1812, formulated in the 1840-1850s under the direct supervision of the emperor. The methodological basis of the study is the systematic examination of historical sources (including visual) and of facts obtained from unpublished archival documents. The study's main results consist in dating the later corrections of the picture to the first half of the 20th century and the reassessment of the painting's role during the reign of Nicholas I. The relevance of the obtained results lies in their practical application (for museum restoration), as well as in the theoretic sphere by inciting to rethink the concept of "the people's war" in the history of Russia during the first half of the 19th century. During Alexander's reign this concept dominated the historiography of the Patriotic War of 1812, while during Nicholas's rule it was substantially reformed, finding reflection in the painting "The Battle of Smolensk".

Key words: Peter Hess, Nicholas I, Patriotic War, Winter Palace, restoration, Smolensk, Hermitage, battle painting, A. I. Mikhailovsky-Danilevsky, L. I. Kihl.

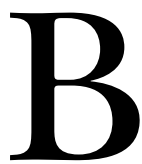

1839 г. по приглашению Николая I в Санкт-Петербург из Мюнхена приехал батальный живописец, придворный художник баварского короля Людвига I, Петер Хесс. По заказу императора ему предстояло написать серию из 12 крупноформатных живописных картин, представляющих основные сражения Отечественной войны 1812 г. В настоящий момент 9 из 12 картин серии хранятся в Государственном Эрмитаже.
История создания этой серии, а также её содержание были тщательно изучены сотрудниками Государственного Эрмитажа Б. И. Асварищем и Г. В. Вилинбаховым. В альбоме «Отечественная война 1812 года в картинах Петера Хесса» [1] используя ранее не изученные архивные материалы, исследователи воссоздали историю получения Хессом императорского заказа, процесс работы художника, детали взаимоотношений заказчика и живописца, дальнейшую судьбу 
серии картин при дворе, а затем, в музее. Также авторы подробно рассмотрели содержание каждой отдельной картины серии в сопоставлении с историческими реалиями войны 1812 г., биографиями её участников и историей униформологии.

В настоящей статье мы сосредоточим своё внимание лишь на одной из 12 картин серии «Сражении под Смоленском» (1846) и попытаемся дополнить выводы наших предшественников новой фактической информацией, а также проанализировать содержание картины в историческом и идеологическом контексте николаевской эпохи.

Для выполнения заказа Петер Хесс вернулся в Мюнхен и присылал картины в СанктПетербург по мере их готовности. В октябре 1846 г. ко двору прибыло четвертое по счёту полотно «Сражение под Смоленском». Как и всем произведениям, созданным по высочайшему заказу, этой картине предстояло выдержать строгий экзамен перед императором. Осмотрев картину в Зимнем дворце, Николай выразил свое полное удовольствие, но вместе с тем, велел передать Хессу некоторые замечания, касающиеся ошибок в пропорциях $[1,30]$. Давая ответ, художник защищал своё произведение и объяснял все нарушения правил обычной перспективы требованиями художественной выразительности. Картина была принята заказчиком и размещена в Зимнем дворце. Вскоре, в 1848 г., Николай повелел изготовить её копию ученикам батального класса петербургской Академии художеств «...для Всемилостивейшего пожалования в дар городу Смоленску» [2, л. 213]. Руководство Академии поручило выполнение заказа молодому художнику Богдану Грейму под руководством профессора Б. П. Виллевальде и оценило эту работу в две тысячи рублей серебром. По завершении работы копия Б. Грейма была выставлена в Зимнем дворце вместе с оригиналом картины «Сражение под Смоленском» П. Хесса для сравнения. Осмотрев оба полотна, император остался недоволен работой копииста и велел Грейму внести изменения в созданную им копию с картины Хесса (Б. И. Асварищ ошибочно предположил, что по указу Николая I изменения были внесены в $о р и$ гинал картины Хесса - $[1,32])$ :

«Господину Министру императорского двора

Обер-гофмаршала графа Шувалова

Рапорт

Начальник 2 Отделения Эрмитажа г. Бруни донес мне, что Государь Император по осмотре 18 сего Мая, выставленной в нижнем этаже, в комнатах бывших Государыни Цесаревны, копии написанной художником Греймом с картины профессора Гессе: "Сражение под г. Смоленском”, Высочайше повелеть изволил художнику Грейму сделать некоторые в ней исправления, по указанию Его Величества. <...>

26 Мая 1853 в Царском селе» - [2, л. 275].

Грейм покорно выполнил волю императора, но просил увеличить плату за свою работу, с учётом внесения исправлений, в чём получил отказ:

«...Шшибки, оказавшиеся в копии с картины: Сражение при Смоленске, исправлены мною по замечаниям, сделанным Его Императорским Величеством. Имея честь донести о сем Вашему Сиятельству, осмеливаюсь вместе с тем представить на милостивое усмотрение Ваше просьбу мою о прибавке к назначенным за копию сию 2000 руб. сер. <..> Б. Грейм.

31 Мая 1853»- [2, л. 271];

«Господину художнику Грейму.

Уведомляю Вас, что вместе с сим сообщено мною <...> Высочайшее повеление об уплате 2000 руб. сер. за написанную вами копию с картины профессора Гессе: Сражение при Смоленске; на увеличение же платы за сию копию Высочайшего соизволения не последовало потому что Его Величество выполнением оной не изволил остаться доволен.

Министр Императорского двора граф Адлерберг.

31 Мая 1853»- [2, л. 278] (Здесь и далее курсив мой - М. Ш.).

Когда копия Грейма была окончательно готова, её отправили в Смоленск в качестве монаршего подарка местному дворянскому собранию. Оригинальное полотно Хесса осталось в Зимнем дворце.

На данный момент картина П. Хесса «Сражение под Смоленском» находится в Государственном Әрмитаже (ГЭ 5905; х., м., 224 х 356 см.), а копия, выполненная Б. Греймом, хранится в Смоленском государственном музее-заповеднике под названием «Выход жителей из Смоленска 6 августа 1812 г.» (СМЗНВ 11106/14; х., м., 205 х 420 см.). На оригинальной эрмитажной картине Хесса существуют две записи: фигура священника в правом нижнем углу картины и икона в руках у женщины, идущей в толпе покидающих 


\section{Исторический журнал: научные исследования № 3 (33) • 2016}

DOI: $10.7256 / 2222-1972.2016 .3 .18065$

Смоленск горожан, закрыты тонировкой нейтрально-коричневого цвета. Они отчетливо видны под инфракрасным излучением [1, 32]. Копия с картины Хесса, выполненная Греймом, в настоящий момент находится в плачевном состоянии, имеет множество прорывов и навёрнута на вал. Однако имеющиеся фотографии с этой картины позволяют утверждать, что фигура священника и икона на ней присутствуют.

Возникает очевидный вопрос о природе записей, существующих в настоящий момент на әрмитажной картине Хесса. В архивных документах, освещающих историю создания оригинала картины «Сражение под Смоленском» Хесса и копии Грейма, речь идёт о внесении «исправлений» именно в копию. Несмотря на ранее упомянутые замечания императора к перспективному построению этой картины Хесса и существование прецедентов внесения исправлений в оригинальные полотна баварского живописца петербуржскими художниками по замечаниям заказчика (а после его смерти, и Александра II) $[1,34]$, в данном случае у нас нет оснований предполагать, что записи, существующие ныне на эрмитажной картине Хесса, выполнены по приказу Николая I.

Относительно того, когда появились упомянутые записи на оригинальной картине Хесса, мы не можем дать окончательного ответа. Изобразительные источники свидетельствуют о том, что не только в 1853 г., но и в 1912 г., эти записи на полотне ещё отсутствовали. Рассмотрим некоторые из этих источников.

На акварели Э. Гау «Третья комната военной живописи» 1866 г. (ГЭ ОР-14364), запечатлевшей вид зала первой запасной половины Зимнего дворца с картинами Хесса, ясно видна не только сама картина «Сражение под Смоленском», но и фигура священника, расположенная в правой нижней её части. Также эта картина воспроизведена без записей в 1887 г. в альбоме: «Иллюстрированная Отечественная война 1812 года: по поводу исполнившегося семидесятипятилетия событий означ. войны / 12 фотограф. с картин П. Гесса, находящихся в Императорском Зимнем дворце с поясн. текстом, пересмотр. и испр. ген.-майором Н. Ф. Дубровиным. СПб.: изд. И. Гофферт, 1887» [3, 10]. Кроме того, во множестве иллюстрированных альбомов, изданных к столетнему юбилею Отечественной войны, широко праздновавшемуся в 1912 г., эта картина также воспроизведена с наличествующими священником и иконой, а в одном из них под фотографией прямо указано: «с картины, находящейся в Зимнем дворце» $[4,53]$. Таким образом, с большой уверенностью можно утверждать, что записи на эрмитажной картине Хесса относятся уже к ХХ в. и выполнены не ранее 1912 г.

Изучение документов из Архива Государственного Эрмитажа, фиксирующих различные манипуляции с этой картиной, проводившиеся в музее, к сожалению, не принесли результатов. Однако в архиве Отдела реставрации станковой живописи Государственного Эрмитажа хранится два протокола реставрации картины «Сражение под Смоленском» П. Хесса 1947 г. и 1990 г. В протоколе реставрации, проведенной в 1947 г., после возвращения картины в Эрмитаж из Кронштадтского ночного санатория при военно-морском госпитале [1, 34], упомянуты отставания красочного слоя, выкрошки, побитости, помутнение лака и сильное загрязнение полотна, устранённые в ходе реставрации [5, л. 1об.]. О существовании на картине записей никаких упоминаний нет. В протоколе следующей реставрации 1990 г. среди прочих утрат и потёртостей упомянуто: «...в правой части большой фигурный прорыв холста с изменившимися в тоне записями» [6, л. 1об.]. Эти свидетельства не дают достаточных оснований для каких-либо определённых выводов. Мы можем позволить себе лишь крайне осторожно предположить, что упомянутые записи были сделаны во время реставрации 1947 г., после которой картина «Сражение под Смоленском» вошла в состав выставки «Героическое военное прошлое русского народа», проходившей в Эрмитаже на протяжении 1950-х гг.

Переходя ко второй части нашего исследования, мы попытаемся проанализировать содержание картины «Сражение под Смоленском» в историческом и идеологическом контексте николаевской эпохи. Важно отметить, что императорский заказ масштабной серии картин об Отечественной войне 1812 г. с самого начала нёс на себе большую идеологическую нагрузку. Полотна Хесса были предназначены для одной из так называемых «комнат военной живописи» первой запасной половины Зимнего дворца. В одном из писем Д. П. Северина П. М. Волконскому от 19.08.1840 сказано: «Господин Хесс получил обмеры, которые определяют размеры его картин, и ожидает модели униформы и оружия, которые господин генерал-майор Киль должен ему отправить» - [2, л. 59]. Это упоминание, а также полное соответствие размеров восьми 
больших и четырёх малых полотен Хесса размерам простенков «Третьей комнаты военной живописи» (ныне зал № 285) свидетельствуют о том, что формат, а возможно, и количество картин серии были определены, в первую очередь, исходя из параметров конкретного помещения, для которого они предназначались. Созданная по желанию Николая I анфилада «комнат военной живописи» должна была наравне с Военной галереей 1812 г. стать мемориалом военной доблести и славы русской армии в императорской резиденции. Судя по упоминавшейся выше акварели Э. Гау 1866 г., представляющей вид Третьей комнаты военной живописи с картинами Хесса, полотна были размещены в зале в «хронологическом» порядке изображённых на них событий войны: «зритель», шедший по анфиладе залов первой запасной половины (со стороны личных покоев императорской фамилии), последовательно «прочитывал» историю войны в картинах. Полную развеску картин в зале позволяет реконструировать сопоставление упомянутой акварели Э. Гау, изображающей вид половины Третьей комнаты военной живописи, с «Описью портретов и баталических картин в Зимнем дворце» $[7,15]$.

Деятельность Николая I по увековечиванию военной истории России в 1830-е гг. очевидным образом связана, с одной стороны, с годовщиной капитуляции Наполеона в 1814-м г., а с другой стороны, с политической ситуацией того времени: польское восстание 1830-31 гг., нарастание революционных настроений в Европе подталкивали к различным историческим и историософским параллелям со «славным 1812 годом» $[8,188-191]$. В сложной и нестабильной политической обстановке перед Николаем I, как и перед его предшественниками, стояла задача формирования новой идеологической модели, способной обеспечить прочную основу его царствования как внутри страны, так и на мировой арене. Николай Павлович, как показал Р. Уортман, избрал для себя сценарий заботливого, всевидящего и строгого отца Российской империи, гаранта династической стабильности [9, 342-347]. Не имея персональной истории «славы и храбрости», император был вынужден обратиться к истории царствования своего предшественника. Александр I - освободитель Европы, спаситель России, объединивший все сословия русского общества и все европейские народы, в николаевскую эпоху был превращён в «ангела-хранителя» не только названного в его честь цесаревича Александра Николаевича, но и всей России.

В 1832 г. по указанию Николая I были возобновлены работы по возведению храма Христа Спасителя, в 1834 г. открыта Александровская колонна на Дворцовой площади, в 1835 г. объявлен публичный конкурс на создание проектов памятников на полях важнейших сражений Отечественной войны, в 1836 г. А. И. МихайловскийДанилевский получает «высочайшее повеление» написать историю наполеоновской кампании, в 1837 г. перед Казанским собором установлены памятники Кутузову и Барклаю-де-Толли [10, 611-630; 11, 277-278], в августе того же года близ Вознесенска прошли демонстративные манёвры в честь 25-ти летней годовщины окончания войны, в 1839 г. на Бородинском поле так же маневрами масштабно отпраздновали годовщину окончания наполеоновской кампании.

Летом 1839 г. прибывший в Санкт-Петербург Петер Хесс получил высочайший заказ на создание рассматриваемой нами серии картин и приглашение на праздник в Бородино. Программа торжественных мероприятий, тщательно готовившаяся под личным контролем императора, включала в себя военные сборы, открытие монумента в честь подвигов русской армии, награждение ветеранов войны и показательные учения войск. Среди прочего на Бородинском поле при большом стечении гостей всех рангов были проведены манёвры и своего рода историческая реконструкция Бородинской битвы, в ходе которой Николай лично возглавил «русские» войска и «переиграл» ход сражения [12, 99]. Специально для иностранных гостей, приглашённых на этот праздник, император поручил прославленному военному историку А. И. МихайловскомуДанилевскому сделать выдержку из его только что оконченного «Описания Отечественной войны в 1812 году» и издать историю Бородинского сражения отдельной книжкой [13, 44]. Здесь нам хотелось бы оспорить точку зрения С. А. Малышкина: «...выходу отдельной книги о Бородинском сражении уже ничего не могло помочь. Через Чернышёва <...> император запросил историка: “...изволили Вы, милостивый государь, по собрании в Бородине сведений, сделать в сочинении Вашем некоторые нужные исправления, кои без сомнения послужат ещё к большему улучшению превосходного труда Вашего”. Но учёный не “соизволил” и на полках Военно-исторического архива навсегда осталась лежать рукопись Бородинской битвы с четырьмя цветными, 


\section{Исторический журнал: научные исследования № 3 (33) • 2016}

DOI: 10.7256/2222-1972.2016.3.18065

прекрасно выполненными картами поля боя»$[13,46]$. В фондах Российской национальной библиотеки нам удалось обнаружить печатные издания авторства Михайловского-Данилевского на русском («Бородинская битва 26 августа 1812 года с присовокуплением описания дела, происходившего 24 августа при Шевардине. С 4 планами. СПб: Военная типография, 1839») и французском языках («Bataille de Borodino (26 Aout 1812) et description de Laffaire du 24 Aout pres Chevardino. S.Petersbourg: Imprimerie du Ministere de la Guerre, 1839»). Также можно предположить, что именно эта книжка упомянута в письме начальника Второго отделения Эрмитажа Ф. И. Лабенского от 26.06.1844: «Его Светлости Господину Министру Императорского Двора. <...> Имею честь донести, что сего же числа получен мною из С. Петербургской Таможни ящик с картиною писанной мюнхенским живописцем Гессем, изображающей "Бородинское Сражение", который и вскрыт при Таможенном Чиновнике. При означенной картине оказалось 1) Краткое рукописное объяснение оной; 2) небольшая печатная книжка, содержащая рассказ о Бородинском сражении, на французском языке. Действительный Статский Советник Лабенский» - [2, л. 134].

Все эти мероприятия активно освещались в прессе. Именно в ходе юбилейных торжеств 1839 г. история войны1812 г. с невиданным до того размахом и пафосом была использована для пропаганды представления о патриархальных истоках русского самодержавия. Отечественная война была представлена как «эпоха развития врождённых качеств русского народа, благоговения к вере, беспредельной преданности царю и Отечеству» $[8,201]$. Весь комплекс столь тщательно готовившихся праздничных мероприятий позволял в нужном императору духе канонизировать память о войне.

Мы позволили себе несколько отклониться от рассматриваемой темы, чтобы подчеркнуть прямую связь между интересующим нас живописным произведением Хесса и вербальным текстом истории войны, формировавшимся под контролем императора в эти же годы. Обнаруженное нами в Российском государственном историческом архиве письмо А. И. Михайловского-Данилевского [2, л. 149] показывает, что историк был непосредственно причастен к процессу создания серии картин Хесса. В 1845 г. он писал министру двора В. Ф. Адлербергу с вопросом о том, присутствует ли в заказанной Хессу серии сюжет, посвящённый подвигу генерала Д. П. Неверовского при Красном. На свой запрос историк получил немедленный ответ, из которого следовало, что истории подвига Д. П. Неверовского нет среди заказанных картин [2, л. 151]. Однако в 1855 г. Хесс прислал в СанктПетербург картину под названием «Подвиг генерала Неверовского под Красным» - единственный во всей серии случай, когда в названии обозначено имя героя войны. Чрезвычайно соблазнительно предположить, что этот эпизод был «запечатлён» П. Хессом именно благодаря вмешательству А. И. Михайловского-Данилевского, тем более, что сюжет картины в точности соответствует описанию сражения под Красным в книге историка. Особому интересу Михайловского-Данилевского к этому заказу могли способствовать близость предмета и задачи: мемориализация событий именно Отечественной войны была единственной целью большой и дорогостоящей серии живописных картин. К сожалению, мы не располагаем никакой информацией, свидетельствующей о знакомстве и непосредственном общении между художником и историком. Работа над живописной серией велась Хессом под руководством и при живейшем участии генерал-майора свиты Его Императорского Величества Льва Ивановича Киля, роль которого в создании и первой интерпретации этих картин до сих пор оставалась недооцененной.

Л. И. Киль, происходивший из старинного курляндского служилого рода, начал свою карьеру в 1813 г. корнетом при командире Российсконемецкого легиона генерал-адъютанте графе Л. Г. Вальмоден-Гимборне $[14,82]$. Киль отличился в ряде сражений заграничного похода и уже в 1815 г. был назначен поручиком по квартирмейстерской части в свиту Его Императорского Величества и служил в канцелярии начальника Главного Штаба императора Александра I князя П. М. Волконского [15, 136]. Оставаясь вплоть до 1819 г. в Париже, Киль работал над созданием серии изображений мундиров русской армии, чем заслужил себе репутацию специалиста и знатока в области военной униформы. По возвращении в Россию Лев Иванович поступил на службу к цесаревичу Константину Павловичу адъютантом, а в 1831 г. после смерти своего покровителя был назначен флигель-адъютантом императора Николая I. В 1832 г. Киль стал почётным вольным общником петербуржской Академии художеств, в 1835-м г. за отличие по службе произведён в генерал-майоры и зачис- 
лен в свиту императора Николая I, в 1844 г. назначен начальником над русскими художниками в Риме (до 1850 г.) [15, 139].

В 1839 г. именно Килю было поручено сопровождать Хесса в путешествии по местам основных сражений Отечественной войны для непосредственного знакомства художника с историческими реалиями, которым он должен был неотступно следовать в своих будущих произведениях. После выполнения всех необходимых натурных зарисовок, сбора сведений о сражениях у живых свидетелей войны, снятия копий с портретов участников Отечественной войны из Военной галереи Зимнего дворца и высочайшего утверждения эскизов к будущим картинам, П. Хесс для выполнения заказа вернулся в Мюнхен. С этого момента и вплоть до 1851 г. его постоянным консультантом, инспектором и «художественным критиком» в Мюнхене выступал Л. И. Киль.

Коротко опишем механизм обеспечения работы художника и контроля над ней. Все летние сезоны Киль находился в Мюнхене, регулярно посещая ателье Хесса, обсуждая с ним создаваемые и только планируемые произведения, консультируя художника по вопросам исторических реалий, проверяя на предмет ошибок уже готовые картины перед отправкой их в СанктПетербург, и сообщая министру Императорского Двора П. М. Волконскому о ходе и успехах работы. В зимние сезоны, которые Лев Иванович по состоянию здоровья и долгу службы проводил в Италии, надзор над художником осуществлял русский посланник в Мюнхене Д. П. Северин, также подробно сообщавший о положении дел Хесса в Министерство императорского двора. Художник, в свою очередь, передавал Килю или Северину просьбы о необходимых для его работы исторических материалах, которые через П. М. Волконского и военного министра А. И. Чернышёва разыскивались и доставлялись живописцу.

Как уже было упомянуто, Лев Иванович Киль выступал и первым интерпретатором работ Хесса. В длинных и пространных письмах Волконскому Киль описывал только что оконченные и ещё не отправленные заказчику картины. Однако, помимо экфрасиса живописных произведений, в этих текстах появляется и идеологическая их интерпретация. Важно подчеркнуть, что Киль находился в довольно трудном положении между заказчиком, с его личной позицией и «непроговоренной» официальной идеологией царствования, и художником, обладавшим точкой зрения на изображаемые события, сформированной европейским визуальным и вербальным контекстом. Таким образом, Килю приходилось самостоятельно улавливать и транслировать художнику «официальный взгляд» на изображаемые события, а затем описывать и интерпретировать готовые произведения, подчёркивая те их черты, которые, в представлении Льва Ивановича, в наибольшей степени соответствовали официальной идеологии. Также перед Килем, как государственным служащим на жаловании, стояла задача постоянного оправдания необходимости собственной службы [16, 269-280]. В письмах он не только подробно перечислял все ошибки, исправленные в изображениях мундиров различных родов войск, но и неоднократно подчёркивал свою в некотором смысле уникальную роль очевидца и носителя «живой памяти» о событиях войны:

«30 лет истекли с той достопамятной эпохи; большинство действующих лиц сей великой драмы умерли; постарели; портреты художника Доу были бы достаточно хороши, особенно те, что написаны с натуры, если бы они всё время находились в соответствии с позами и манерой освещения, в которых художник расположил фигуры [на своих картинах - М. ШІ. ]. <...> Господин П. Хесс <...> предпринял неслыханные усилия, чтобы достигнуть при помощи сих несовершенных материалов наибольшей схожести. Я способствовал тому, насколько мог, через свою память о тех людях, которые были мне знакомы из того времени» - [2, л. 106] (оригинал по-франц.).

Ещё одним общим местом в письмах Киля является «историческая точность» изображений:

«... я прилагаю всё своё усердие и наиболее скрупулёзное внимание, чтобы наблюдать за исторической военной точностью, чтобы высокие намерения Императора <..> были бы достойно исполнены нашими совместными усилиями сохранить наибольшую историческую точность...»- [2, л. 74] (оригинал по-франц.);

«Прежде чем приступить к исполнению этой картины, историческая точность была обсуждена и углублена с наиболее скрупулёзным вниманием...»- [2, л. 101] (оригинал пофранц.).

Первоначально исходившее от императора требование соответствия картин строгой исто- 


\section{Исторический журнал: научные исследования № 3 (33) • 2016}

DOI: 10.7256/2222-1972.2016.3.18065

рической точности было существенно развито Килем. Так, в описании «Сражения при Вязьме», он, подчёркивая «усилия сохранить наибольшую историческую точность» [2, л. 74], считает нужным объяснить существующие в картине отступления от «регламента»:

«Мне остаётся заметить Вашей Светлости, что аномалии, которые туда [в картину - M. $\amalg$.] просочились, были оставлены [неразборчиво]. Художник хотел изобразить в Сражении при Вязьме переход от летней кампании к зимней. Уже четыре месяца все сражались без отдыха, и было невозможно сохранить строгий порядок. Так генерал Чоглоков и его адъютант одеты в парадной форме, в то время как офицеры на переднем плане одеты в сюртуки и картузы (каскетки). В последующих битвах костюмы лучше соответствуют различным сезонам» $-[2$, л. 74$]$ (оригинал по-франц.).

В соответствии с исторической правдой факта все войска должны быть изображены на картине в соответствующей им и сезону форме, с нужным количеством пуговиц и т. д. Однако художник, и Киль вместе с ним, вступает в противоречие с «нормой» в пользу художественной правды и изображает «реальное» положение дел. Специально разъясняя этот момент, Л. И. Киль защищает себя и П. Хесса от обвинений в незнании исторических реалий (ошибке) и интерпретирует изображённое как дань исторической истине в нарушение правил. Однако знатокам истории Отечественной войны хорошо известно, что к осени 1812 г. состояние русской армии было таковым, что не могло идти и речи об образцовом порядке в обмундировании. Мундиры были не только значительно изношены, но и сильно перемешаны. Лев Иванович, как очевидец и участник событий, не мог не знать об этих бытовых реалиях войны. «Историческая точность» в интерпретации Хесса и Киля в данном случае предполагала не изображение бытовых «случайностей», а обязательное наличие определённого «порядка».

Наконец, Киль, описывая и интерпретируя картины Хесса, представляет и своё прочтение идеологии истории Отечественной войны 1812 г. Об интересующей нас в первую очередь картине «Сражение под Смоленском» он пишет:

«... введение в кровавую драму бессмертной кампании 1812 года. Это не просто борьба между двумя дисциплинированными и натренированными армиями. Это - яростная война против целой нации, которую он попытался выразить группами на авансцене справа: народ в бегстве, спасающий своих ларов и пенатов, достопочтенный священник во главе, взывающий к божьему гневу на жестокого захватчика $<\ldots>$ Бегущий народ, процессия, несущая Богоматерь Смоленскую. На первом плане картины находится генерал-аншеф военный министр Барклай-де-Толли, сидящий под деревом, окружённый генералами Раевским, Ермоловым, Уваровым, Неверовским и Платовым» - $[2$, л. 168] (оригинал по-франц.).

В интерпретации Киля широко распространённая в эпоху Александра I концепция «народной войны» претерпевает существенные изменения. Наиболее ярко воплощённый в «Азбуке 1812 года» образ народной войны, предполагает модель надсословного единства, представленного храбрыми крестьянами с вилами и рогатинами, «русским Сцеволой», старостихой Василисой, партизанами и т. д., совместно дающими отпор врагу. Однако у Хесса представлен образ не сопротивляющегося врагу и беззащитного «народа в бегстве», уповающего в своём спасении на Бога и императорскую армию. Интересно отметить, что на картине «Сражение под Смоленском» в группе «бегущих» присутствуют не только старики, женщины и дети, но и «обороноспособные» мужчины. В серии Хесса, благодаря интерпретации Киля, проявляется характерное для николаевской идеологии понимание места и роли народа в истории войны 1812 года. Народу отведена здесь роль беззащитной и набожной «процессии», судьба которой находится в руках «божественного провидения» и организованной армии. Обратившись в этом контексте к описанию сражения при Смоленске в труде А. И. Михайловского-Данилевского 1839 г., мы обнаружим схожее представление образа «народа» и его роли в войне $[17,120]$. В тексте историк представляет три основные группы действующих лиц: «народ», в панике бегущий из города и уповающий на божественное возмездие, «армию», храбро вступающую в захваченный французами горящий город, и «штаб», вдохновляющий войска мудрыми приказаниями и собственным примером [17, 119-122]. Такая расстановка сил во многом соответствовала официальному взгляду на историю войны, сформулированному ещё в 1837 г. в статье $\Phi$. В. Булгарина «Правда о 1812-м годе, служащая к исправлению ошибки, вкравшейся в мнение современников» [18, 26-28]. Ставя вопрос о том, кому принадлежит роль «спасителя России» в Отечественной 
войне, Булгарин отказывает в ней Кутузову и Барклаю-де-Толли, полководцам «великих величием царя и русского народа» $[18,26-28]$, и приходит к выводу, что «Россия спасла сама себя, упованием на Бога, верностью и доверенностью к своему Царю» $[18,28]$. Таким образом, Булгарин, как и Михайловский-Данилевский, представляет роль народа в Отечественной войне в уповании на Бога и царя. В «Сражение под Смоленском» Хесса образ народа (мирного населения) в От- ечественной войне получил визуальное воплощение в полном соответствии с «официальной» точкой зрения на этот вопрос, сформированной в 1830-е гг.

Смеем надеяться, что столь подробное рассмотрение мелких деталей одного живописного заказа и отдельного произведения позволят глубже понять общий процесс формирования визуального образа национальной истории, проходивший при дворе Николая I.

\section{Библиография:}

1. Асварищ Б. И., Вилинбахов Г. В. Отечественная война 1812 года в картинах Петера Хесса. СПб.: Изд. Гос. Эрмитажа, 2013. $118 \mathrm{c}$.

2. Дело о вызове в Санкт-Петербург мюнхенского живописца П. Гесса. 1839 г. // Российский государственный исторический архив. Ф. 472. Оп. 17 (2/934). Д. 7. Л. 1-333.

3. Иллюстрированная Отечественная война 1812 года: по поводу исполнившегося семидесятипятилетия событий означ. войны / 12 фотограф. с картин П. Гесса, находящихся в Императорском Зимнем дворце с поясн. текстом, пересмотр. и испр. ген.-майором Н. Ф. Дубровиным. СПб.: изд. И. Гофферт, 1887. 26 с.

4. Божерянов И. Н. Война русского народа с Наполеоном. СПб.: Общество попечения о бесприютных детях, 1911.132 с.

5. Протокол реставрации № 2971. 1947 г. // Архив Отдела реставрации станковой живописи Государственного Эрмитажа. Л. $1-2$.

6. Протокол реставрации № 15360. 1990 г. // Архив Отдела реставрации станковой живописи Государственного Эрмитажа. Л. 1-2.

7. Опись портретов и баталических картин, находящихся в Зимнем дворце // Архив Государственного Эрмитажа. Ф.1. Оп. 6А. Д. 133. Л. 1-43.

8. Тартаковский А. Г. 1812 год и русская мемуаристика: опыт источниковедческого изучения. М.: Наука, 1980. 312 с.

9. Уортман Р. С. Сценарии власти. Мифы и церемонии русской монархии / Пер. С. В. Житомирской. Т. 1. М.: О.Г.И., 2002. $608 \mathrm{c.}$

10. Витберг Ф. О памятниках Отечественной войны // Русская старина. 1912. Т. 152. № 12. С. 611-630.

11. Ашик В. А. Памятники и медали в память боевых подвигов русской армии в войнах 1812,1813 и 1814 годов и в память императора Александра І. СПб.: тип. т-ва п/ф. «Электро-тип. Н. Я. Стойковой», 1913. 393 с.

12. Хесс Э. Русский дневник / Пер. с нем. и прим. Б. И. Асварища. СПб.: Ахіота, 2007. 231 с.

13. Малышкин С. А. История создания А. И. Михайловским-Данилевским «Описания Отечественной войны в 1812 году» // Материалы Всеросс. научн. конф. Проблемы изучения истории Отечественной войны 1812 года. Саратов: Изд. Саратовского гос. университета, 2002. С. 36-47.

14. Кусакин А., Подстаницкий С. Кирасир-художник Лев Иванович Киль // Русское искусство. 2005. № 4. С. 82-87.

15. Валькович Л. М. «Мундиры российской армии» Л. И. Киля // Труды Российского государственного военно-исторического архива. 1998. Вып. II. С. 135-143.

16. Яйленко Е. Миф Италии в русском искусстве первой половины XIX века. М.: Новое литературное обозрение, 2012.344 с.

17. Михайловский-Данилевский А. И. Описание Отечественной войны в 1812 году. СПб.: Военная типография, 1839. Ч. 2. 449 c.

18. Булгарин Ф. «Правда о 1812-м годе, служащая к исправлению ошибки, вкравшейся в мнение современников» // Северная пчела. 1837. №7 (11 янв.). С. 26-28.

\section{References (transliterated):}

1. Asvarishch B. I., Vilinbakhov G. V. Otechestvennaya voina 1812 goda v kartinakh Petera Khessa. SPb.: Izd. Gos. Ermitazha, 2013. $118 \mathrm{~s}$.

2. Delo o vyzove v Sankt-Peterburg myunkhenskogo zhivopistsa P. Gessa. 1839 g. // Rossiiskii gosudarstvennyi istoricheskii arkhiv. F. 472.0 . 17 (2/934). D. 7. L. 1-333.

3. Illyustrirovannaya Otechestvennaya voina 1812 goda: po povodu ispolnivshegosya semidesyatipyatiletiya sobytii oznach. voiny / 12 fotograf. s kartin P. Gessa, nakhodyashchikhsya v Imperatorskom Zimnem dvortse s poyasn. tekstom, peresmotr. i ispr. gen.maiorom N. F. Dubrovinym. SPb.: izd. I. Goffert, 1887. 26 s.

4. Bozheryanov I. N. Voina russkogo naroda s Napoleonom. SPb.: Obshchestvo popecheniya o bespriyutnykh detyakh, 1911.132 s.

5. Protokol restavratsii № 2971.1947 g. // Arkhiv Otdela restavratsii stankovoi zhivopisi Gosudarstvennogo Ermitazha. L. 1-2.

6. Protokol restavratsii № 15360. 1990 g. // Arkhiv Otdela restavratsii stankovoi zhivopisi Gosudarstvennogo Ermitazha. L. 1-2.

7. Opis' portretov i batalicheskikh kartin, nakhodyashchikhsya v Zimnem dvortse // Arkhiv Gosudarstvennogo Ermitazha. F.1. Op. 6A. D. 133. L. 1-43.

8. Tartakovskii A. G. 1812 god i russkaya memuaristika: opyt istochnikovedcheskogo izucheniya. M.: Nauka, 1980. 312 s. 


\section{Исторический журнал: научные исследования № 3 (33) • 2016}

\section{DOI: $10.7256 / 2222-1972.2016 .3 .18065$}

9. Uortman R. S. Stsenarii vlasti. Mify i tseremonii russkoi monarkhii / Per. S. V. Zhitomirskoi. T. 1. M.: O.G.I., 2002. 608 s.

10. Vitberg F. 0 pamyatnikakh Otechestvennoi voiny // Russkaya starina. 1912. T. 152. № 12. S. 611-630.

11. Ashik V. A. Pamyatniki i medali v pamyat' boevykh podvigov russkoi armii v voinakh 1812, 1813 i 1814 godov i v pamyat' imperatora Aleksandra I. SPb.: tip. t-va p/f. «Elektro-tip. N. Ya. Stoikovoi», 1913. $393 \mathrm{~s}$.

12. Khess E. Russkii dnevnik / Per. s nem. i prim. B. I. Asvarishcha. SPb.: Axioma, 2007. 231 s.

13. Malyshkin S. A. Istoriya sozdaniya A. I. Mikhailovskim-Danilevskim «Opisaniya Otechestvennoi voiny v 1812 godu» // Materialy Vseross. nauchn. konf. Problemy izucheniya istorii Otechestvennoi voiny 1812 goda. Saratov: Izd. Saratovskogo gos. universiteta, 2002. S. 36-47.

14. Kusakin A., Podstanitskii S. Kirasir-khudozhnik Lev Ivanovich Kil' // Russkoe iskusstvo. 2005. № 4. S. 82-87.

15. Val'kovich L. M. «Mundiry rossiiskoi armii» L. I. Kilya // Trudy Rossiiskogo gosudarstvennogo voenno-istoricheskogo arkhiva. 1998. Vyp. II. S. 135-143.

16. Yailenko E. Mif Italii v russkom iskusstve pervoi poloviny XIX veka. M.: Novoe literaturnoe obozrenie, 2012. $344 \mathrm{~s}$.

17. Mikhailovskii-Danilevskii A. I. Opisanie Otechestvennoi voiny v 1812 godu. SPb.: Voennaya tipografiya, 1839. Ch. 2. 449 s.

18. Bulgarin F. «Pravda o 1812-m gode, sluzhashchaya k ispravleniyu oshibki, vkravsheisya v mnenie sovremennikov» // Severnaya pchela. 1837. №7 (11 yanv.). S. 26-28. 